\title{
A escola e a semiliberdade: a importância do diálogo
}

\author{
School and semi-liberty: the importance of dialogue
}

La escuela y la semilibertad: la importancia del diálogo

\author{
Jacqueline de Oliveira Moreira* \\ Paula Melgaço ${ }^{* *}$ \\ Bruna Simões de Albuquerque ${ }^{* * *}$ \\ Bianca Ferreira Rocha ${ }^{* * *}$ \\ Ana Carolina Ferreira Ribeiro ${ }^{* * * * *}$
}

\begin{abstract}
Resumo
A relação do adolescente autor de ato infracional com o espaço escolar é o tema central deste artigo. Procurou-se refletir sobre o eixo da escolarização na medida socioeducativa de semiliberdade, levando em conta as peculiaridades de tal medida no que concerne aos impasses vividos com a escola. Para isso, realizou-se uma análise tanto da evasão escolar dos adolescentes, destacandose a função da escola em suas vidas e as dificuldades de permanecer no espaço escolar, quanto dos problemas enfrentados por professores na inserção desses alunos. Entender os desafios da escolarização na medida de semiliberdade contribui para uma compreensão ampliada dos impasses na educação hoje, visto que isso demanda uma pesquisa que contemple os jovens e sua relação conflituosa com a escola, a dificuldade dos educadores com a transmissão e a resistência das instituições. Finalmente, sugerem-se saídas para o trabalho da semiliberdade com base no entendimento da escola como lugar de vida.
\end{abstract}

Palavras-chave: Semiliberdade. Medida socioeducativa. Adolescência. Educação. Professor.

\footnotetext{
Texto recebido em setembro 2013 e aprovado para publicação em junho de 2014.

"Doutora em Psicologia Clínica pela PUC SP, mestra em Filosofia pela Universidade Federal de Minas Gerais (UFMG), professora do Programa de Pós-Graduação em Psicologia da PUC Minas (M/D), bolsista produtividade PQ2, psicanalista. Endereço: Avenida Itaú, 525 - Bairro Dom Cabral, Belo Horizonte-MG. CEP 30535-012. Telefone: (31) 3319-4568. E-mail: jackdrawin@yahoo.com.br.

"Mestranda pela PUC Minas, especialista em Psicanálise com crianças e adolescentes, bolsista CAPES Psicóloga. Endereço: Rua Xapuri, 450, ap. 302 - Grajaú, Belo Horizonte-MG. CEP: 30431-214. E-mail: paulamelgaco.psi@gmail.com.

"** Mestra em Psicologia - Psicopatologia e Estudos Psicanalíticos pela Université de Strasbourg, França, Universidade Federal de Minas Gerais, Faculdade de Medicina Grupo de Pesquisa "Subjetividade e Cultura". Endereço: Rua Galba Veloso, 364, ap. 402 - Santa Tereza, Belo Horizonte-MG. CEP: 31015-080. E-mail: bruquerque@gmail.com.

"*m** Mestra em Psicologia pela UFMG. Endereço: Rua Borborema, 1636 - Cachoeira, Belo Horizonte-MG. CEP: 31130-380. E-mail: biancaroch@yahoo.com.br.

${ }^{* * * * *}$ Graduada em Psicologia pela UFMG. Endereço: Rua Monte Alegre, 774, ap. 401 - São Lucas, Belo Horizonte-MG. CEP: 30240-230. E-mail: anaribeiro95@gmail.com.
} 


\begin{abstract}
The relationship between teenagers who have committed infractions and the school environment is the main topic of this article, which aims to reflect on schooling during compliance of social educational measures of semi-liberty, taking into consideration the peculiarities of such measures regarding the impasses with school as an institution. For this purpose, an analysis of drop-out rates (highlighting the role of school in the youngsters' lives and the difficulty to keep attending classes) as well as the problems faced by teachers through the insertion of these students. Understanding the challenges of schooling during semi-liberty measures contributes to a broader comprehension of today's educational deadlocks, as it demands researches that focus on the teenagers in their confrontational relationship with school as well as the difficulties faced by teachers and institutional resistance. Finally the text offers suggestions for the work with semi-liberty from the perspective of school as a place for living.
\end{abstract}

Keywords: Semi-liberty. Social educational measures. Adolescence. Education. Teachers.

\title{
Resumen
}

La relación del adolescente autor de acto infractor con la escuela es el tema central de este artículo. Se procuró reflexionar sobre la escolarización en la medida socioeducativa de semilibertad, considerando las peculiaridades de tal medida en su relación con los impases vividos con la escuela. Para ello, se analizó tanto la evasión escolar de los adolescentes, destacándose la función de la escuela en sus vidas y las dificultades de permanecer ahí, como los problemas enfrentados por profesores en la inserción de esos alumnos. Entender los desafíos de la escolarización en la medida de semilibertad contribuye para la comprensión de los impases en la educación hoy, ya que eso demanda una investigación que contemple los jóvenes y su relación conflictiva con la escuela, la dificultad de los educadores con la transmisión y la resistencia de las instituciones. Finalmente, son sugeridas salidas para el trabajo con la semilibertad desde la comprensión de la escuela como lugar de vida.

Palabras clave: Semilibertad. Medida socioeducativa. Adolescencia. Educación. Profesor. 
relação do adolescente autor de ato infracional com o espaço escolar é o tema que nos move neste artigo. Sabemos que as medidas socioeducativas representam a resposta do Estado ao problema do adolescente envolvido com a criminalidade e se inserem no interior da doutrina de proteção integral à criança e ao adolescente, que, de acordo com o Estatuto da Criança e do Adolescente, são sujeitos em estado peculiar de desenvolvimento.

O processo de operacionalização das medidas convoca profissionais de diferentes campos científicos, como juristas, assistentes sociais, psicólogos, educadores e outros agentes, que oferecem seu saber específico para o projeto de responsabilização desses sujeitos diante de seu ato infracional. E no sentido de oferecer diretrizes mais concretas para regulamentação da aplicação das medidas, surge o Sistema Nacional de Atendimento Socioeducativo (Sinase) (Lei Federal 12.594/2012), que pretende organizar a execução com base nos eixos: família, relações sociocomunitárias, profissionalização, escolarização, cultura, esporte, lazer e saúde. A reflexão sobre cada eixo é importante, mas optamos por pensar as dificuldades e possibilidades de efetivação da escolarização dos adolescentes em cumprimento da medida socioeducativa de semiliberdade. Nesse sentido, parece pertinente compreender as funçōes da escola na vida dos jovens.

Sabemos que a criação de instituições educacionais para crianças e jovens data do período posterior à Revolução Industrial (Rizzo, 2003; Paschoal \& Machado, 2009). Antes disso, a educação do "pequeno adulto" acontecia no seio da família, espaço de transmissão de valores, técnicas de trabalho e conhecimento. Todavia o processo de passagem do modo de organização feudal para o industrial cooptou as crianças das famílias para o trabalho nas fábricas. Esse cenário se revelou perigoso para a saúde e para a vida das crianças pobres. Segundo Rizzo (2003):

Criou-se uma nova oferta de emprego para as mulheres, mas aumentaram os riscos de maus-tratos às crianças, reunidas em maior número, aos cuidados de uma única, pobre $\mathrm{e}$ despreparada mulher. Tudo isso, aliado a pouca comida e higiene, gerou um quadro caótico de confusão, que terminou no aumento de castigos e muita pancadaria, a fim de tornar as crianças mais sossegadas e passivas. Mais violência e mortalidade infantil (p. 31).

A reflexão de Paschoal e Machado (2009) aponta para a paradoxal ação das novas instituições escolares diante do problema das crianças desvalidas: por um lado, é inegável o projeto humanista de acolhimento e oferta de uma possibilidade de futuro para essas crianças condenadas ao descaso; por outro, não podemos deixar de ver a face higienista desse processo que responde ao desejo da sociedade de "ver as ruas limpas do estorvo e da sujeira provocados pelas crianças abandonadas" (Paschoal \& Machado, 2009, p. 80). 
No Brasil, o surgimento das instituições escolares, sobretudo para crianças e jovens, está vinculado ao processo de catequização indígena realizado pelos jesuítas, por ordem do rei Dom João III (Ribeiro, 2001). O ponto comum desses movimentos parece ser o desejo de inclusão da criança nas regras e organização da sociedade vigente.

Assim, não podemos negar os problemas paradoxais que se inscrevem na origem da criação das instituições educativas, mas, por outro lado, a inserção no espaço educativo é a mais importante alternativa para a inclusão no mercado de trabalho e na sociedade. Nessa perspectiva, a evasão escolar passa a ser um grave problema.

\section{A escola e a evasão}

Os índices de evasão escolar das crianças e adolescentes de baixa renda são significativos. Segundo dados do relatório do Fundo das Nações Unidas para a Infância (UNICEF, 2011), O direito de ser adolescente, muitas vezes as crianças e os adolescentes não conseguem aprender ou avançar na escolaridade, seja por causa da qualidade do ensino e do ambiente de aprendizagem, seja devido às atribuições domésticas e familiares:

À medida que as séries escolares avançam, aumentam os índices de distorção idade-série e de evasão [...] Em 2009, 13\% das crianças e adolescentes de 10 a 14 anos tinham atraso escolar superior a dois anos. No mesmo ano, do total dos 2,3 milhōes de concluintes do ensino fundamental, 1,09 milhão (ou mais de 47\%) tinham entre 15 e 17 anos: encontravam-se atrasados em seus estudos (Fundo das Naçōes Unidas para a Infância [UNICEF], 2011, p. $31)$.

Esses números são ainda mais relevantes quando a cotação é realizada no contingente de adolescentes que respondem por medidas socioeducativas. Zanela (2010), como citado em Assis e Constantino (2001), revela que, naquele levantamento, " $70 \%$ dos jovens entrevistados já haviam abandonado os estudos", com as seguintes alegações:

A necessidade de trabalhar e a dificuldade em conciliar escola e trabalho, o desentendimento com professores e colegas e, ainda, as constantes reprovaçōes, as dificuldades de aprendizagem, instabilidade nas moradias, problemas emocionais e de saúde (Zanela, 2010, p. 6). 
Volpi (2011) realizou uma pesquisa com 4.245 adolescentes privados de liberdade e verificou que

[...] a grande maioria dos adolescentes pesquisados - 96,6\% - não concluiu o ensino fundamental. A porcentagem de analfabetos é $15,4 \%$. O número de adolescentes que concluíram o $2^{\circ}$ grau, consequentemente, torna-se praticamente nulo -7 num total de 4.245 (cujas informaçóes foram obtidas) -, o que representa a ínfima parcela de $0,1 \%$ (Volpi, 2011, p. 56).

Os resultados alcançados na pesquisa de Volpi (2011) são confirmados nos dados apresentados pelo banco de dados da Diretoria de Gestão da Informação e Pesquisa (DGIP/SUASE, 2013), que revelam uma forte defasagem escolar entre os adolescentes que cumprem medida de semiliberdade em Minas Gerais.

Em 2013, foram acautelados 554 adolescentes. Destes, 37,6\% estavam com 17 anos, sendo essa a idade mais comum no universo da semiliberdade. Contudo, no que tange à escolaridade, $23,7 \%$ dos adolescentes estão no $6^{\circ}$ ano do ensino fundamental. Podemos observar, portanto, que há uma disparidade entre a idade e a série, uma vez que a idade mais expressiva dos adolescentes não corresponde ao índice de escolaridade que eles deveriam ter. Nesse sentido, é possível ainda perceber que, dos adolescentes atendidos em 2013, 91,6\% deveriam estar no ensino médio, mas somente $8,8 \%$ se encontram nesse nível escolaridade, o que revela a grande defasagem escolar presente nos adolescentes que cumprem medida socioeducativa de semiliberdade.

Um dado não menos importante refere-se à porcentagem de adolescentes analfabetos ou que se encontram nos primeiros anos do ensino fundamental, nos quais ocorre a alfabetização. Ainda que pareça ser um número irrelevante, visto que não ultrapassa $2 \%$ do total de adolescentes atendidos na semiliberdade, tal dado revela que há adolescentes que não tiveram acesso à educação ou que, por diferentes motivos, abandonaram a escola muito cedo. Essa realidade materializa o abismo que existe entre a escolaridade e as possibilidades de inserção dos adolescentes no mercado de trabalho, o que se apresenta como um entrave para o trabalho socioeducativo. 
Figura 1. Número absoluto de adolescentes acautelados na medida de semiliberdade em 2013 (jan/nov).

Número absoluto de adolescentes acautelados na medida de Semiliberdade em 2013 (JAN/NOV)

$\frac{\mathbf{N}}{554} \frac{\%}{100,0 \%}$

Distribuição percentual dos adolescentes acautelados na medida de Semiliberdade em 2013, por sexo.

SEXO

\begin{tabular}{cc} 
SEXO & $\%$ \\
\hline Feminino & $2,6 \%$ \\
Masculino & $97,4 \%$ \\
\hline Fonte: Diretoria de Gestão da Informação e Pesquisa - DGIP/SUASE - 2013
\end{tabular}

Distribuição percentual dos adolescentes acautelados na medida de Semiliberdade em 2013, por idade.

\begin{tabular}{cc} 
IDADE & $\%$ \\
\hline 12 & $0,2 \%$ \\
13 & $1,6 \%$ \\
14 & $4,0 \%$ \\
15 & $13,9 \%$ \\
16 & $23,7 \%$ \\
17 & $37,6 \%$ \\
18 & $13,9 \%$ \\
19 & $2,0 \%$ \\
20 & $0,5 \%$ \\
Sem Informação & $2,6 \%$ \\
\hline
\end{tabular}

Fonte: Diretoria de Gestão da Informação e Pesquisa - DGIP/SUASE - 2013

Distribuição percentual dos adolescentes acautelados na medida de

Semiliberdade em 2013, por escolaridade no momento da acolhida.

\begin{tabular}{cc} 
ESCOLARIDADE DO ADOLESCENTE & $\%$ \\
\hline $1^{\circ}$ Ano Ensino Fund. & $0,5 \%$ \\
$2^{\circ}$ Ano Ensino Fund. & $0,4 \%$ \\
$3^{\circ}$ Ano Ensino Fund. & $1,3 \%$ \\
$4^{\circ}$ Ano Ensino Fund. & $3,5 \%$ \\
$5^{\circ}$ Ano Ensino Fund. & $12,0 \%$ \\
$6^{\circ}$ Ano Ensino Fund. & $23,7 \%$ \\
$7^{\circ}$ Ano Ensino Fund. & $18,2 \%$ \\
$8^{\circ}$ Ano Ensino Fund. & $11,1 \%$ \\
$9^{\circ}$ Ano Ensino Fund. & $6,9 \%$ \\
$1^{\circ}$ Ano Ensino Medio & $8,2 \%$ \\
$2^{\circ}$ Ano Ensino Medio & $0,2 \%$ \\
$3^{\circ}$ Ano Ensino Medio & $0,2 \%$ \\
Analfabeto & $0,2 \%$ \\
Nao Sabe/ Nao Respondeu & $5,8 \%$ \\
Sem Informação & $7,7 \%$ \\
\hline
\end{tabular}

Fonte: DGIP/SUASE, 2013.

De forma semelhante, com base em relatos de educadores do Estado de Goiás, Pinheiro (2013) afirma que muitos adolescentes chegam à medida socioeducativa fora da escola ou com vários problemas relacionados a essa instituição. 
Diversos trabalhos acadêmicos produzem hipóteses sobre a relação que esses jovens estabelecem com a escola. Entre eles, Carvalho (2011), em seu estudo sobre a inserção dos adolescentes em liberdade assistida na escola, revela que, para os adolescentes participantes de sua pesquisa, "A escola é uma obrigatoriedade muitas vezes cumprida por conta da expectativa da família e pela demanda da própria medida [. . .]" (p. 142). Ademais, alguns jovens expõem sua dificuldade de lidar com certos conteúdos ministrados na sala de aula por os considerarem irrelevantes para sua vida, bem como com o fato de serem responsabilizados pela diretoria e professores pela maioria dos atos de indisciplina que ocorrem na escola. Outro fator que dificulta a permanência desses jovens no ambiente escolar é o fato de buscarem repostas e soluçôes imediatas para suas vidas, o que dificulta sua permanência na escola e sua inserção num curso profissionalizante que gerará resultados em longo prazo (Gallo \& Willians, 2008).

Para os jovens, a escola se mostra distante dos seus interesses, reduzida a um cotidiano enfadonho, com professores que pouco acrescentam à sua formação, tornando-se cada vez mais uma "obrigação" necessária, tendo em vista a necessidade dos diplomas (Dayrell, 2007, p. 1106).

A bela passagem do conto de Lima Barreto (2010), "O Filho de Gabriela", ilustra a dificuldade do jovem no processo de apreensão das verdades apresentadas na escola:

Eram-lhes as horas de aula um bem triste momento. Não que fosse vadio, estudava o seu bocado, mas o espetáculo do saber, por um lado grandioso e apoteótico, pela boca dos professores, chegava-lhe tisnado e um quê desarticulado. Não conseguia ligar bem umas coisas às outras, além do que, tudo aquilo lhe aparecia solene, carrancudo e feroz. Um teorema tinha o ar autoritário de um régulo selvagem; e aquela gramática cheia de regrinhas, de exceções, uma coisa cabalística, caprichosa e sem aplicação útil. O mundo parecia-lhe uma coisa dura, cheia de arestas cortantes, governado por uma porção de regrinhas de três linhas, cujo segredo e aplicação estavam entregues a uma casta de senhores, tratáveis uns, secos outros, mas todos velhos indiferentes (p. 104).

Tanto a narração de Lima Barreto quanto as considerações de Dayrell representam uma escola desagradável para o adolescente, o que está na contramão com o lugar de vida descrito por Freud (1910/2006) com o acolhimento por parte da escola e dos educadores das questóes e atos trazidos pelos adolescentes. Trata-se, portanto, de "lhes dar o desejo de viver e de oferecer-lhes apoio e amparo numa época da vida em que as condições de seu desenvolvimento os compelem a afrouxar seus vínculos com a casa dos pais e com a família" (Freud, 1910/2006, p. 243). 
É imprescindível ressaltar que acolher não significa desresponsabilizar os adolescentes por seus posicionamentos e nem desrespeitar as normas vigentes na escola, mas escutar aquilo que dizem e que trazem de particular e único. Sabemos que os adolescentes podem se expressar tanto por um ato infracional como por um comportamento passível de ser interpretado como indisciplina. Em ambos os casos, é possível criar um espaço de escuta e acolhimento para o sujeito e a verdade velada nos atos.

Parece-nos importante, aqui, diferenciar ato infracional e indisciplina. Ato infracional ${ }^{1}$ é somente a conduta descrita como crime, já a indisciplina está relacionada ao rompimento de regras e normas da escola.

\section{Dificuldades dos educadores com a inserção de adolescentes autores de ato infracional nas escolas}

Alguns trabalhos (Silva \& Sales, 2009; Alves, 2010) afirmam que os educadores "dizem que estão de mãos atadas frente às crianças que não podem mais ser reprimidas ou chamadas ao dever" (Silva \& Sales, 2009, p. 4). Nesse caso, os educadores criticam uma gama de direitos dispostos no Estatuto da Criança e do Adolescente (ECA) que estariam protegendo excessivamente as crianças e os adolescentes do Brasil. Além disso, Carvalho (2011) mostra que, com a promulgação do ECA, as escolas passaram a ter a obrigação legal de matricular os adolescentes em cumprimento de medidas socioeducativas.

Ainda no que se refere à posição dos professores em relação aos jovens em conflito com a lei, Cardoso (2009) afirma que a escola, em alguns momentos, coloca tais adolescentes "como 'incapazes' de aprender e conviver no ambiente escolar, por considerá-los 'anormais' e potencialmente 'perigosos" (Cardoso, 2009 , p. 2). Assim, acreditam que devam ser vigiados para que não desorganizem a ordem estabelecida pela instituição. Nesse sentido, Alves (2010) revela:

$\mathrm{Na}$ escola circulam as mesmas representações sociais da sociedade sobre o adolescente em conflito com a lei: medo, indiferença, dó, compaixão e hostilidade: há uma forte tendência de reforçar preconceitos e comparaçôes entre o padrão de comportamento do aluno desejado, tido como "normal" e do aluno "problema" (p. 27).

De forma semelhante, Gallo e Willians (2008) enumeram alguns pontos que caracterizam os adolescentes em conflito com a lei, os quais, acreditam, repetemse em diversas culturas. A evasão, o fracasso escolar e a rejeição por parte dos professores são enumerados nessa lista.

1 De acordo com o artigo 103 do Estatuto da Criança e do Adolescente (Lei Federal no 8.069/1990): "Considera-se ato infracional a conduta descrita como crime ou contravenção penal". 
Sobre a relevância da escola na vida dos adolescentes em conflito com a lei, a pesquisa de Silva e Salles (2009) argumenta que os professores acreditam que o trabalho da instituição escolar pode, por exemplo, "oferecer ajuda psicológica, complementar a família na função de cuidado [. . .], enfrentar os problemas relacionados ao uso de drogas, ensinar, orientar, punir" (p. 9). Essa percepção é corroborada pela Lei de Diretrizes e Bases da Educação de 1996 (Lei Federal no 9.394/1996), que prevê mudanças no papel escolar. A partir dessa lei, a escola passou a assumir um papel social até então impensado, já que a aquisição de conhecimento era a função primordial da instituição escolar. Todavia, mesmo que a escola possa oferecer diversos benefícios, alguns professores acreditam que "a interrupção dos estudos é prejudicial por permitir um tempo ocioso e não pela importância da escola na formação do adolescente” (Silva \& Salles, 2009).

É importante apontar também a dificuldade que muitos adolescentes enfrentam para encontrar vaga nas escolas. Esse fato é relatado por Santana, Oliveira e Machado (2012) na experiência de execução da medida socioeducativa no PPSC/UFRGS:

Nos últimos dois anos - com um visível agravamento em 2011 -, muitos dos adolescentes atendidos pelo PPSC/UFRGS não têm conseguido sequer garantir sua vaga no sistema regular de ensino. Daqueles acompanhados em 2011, um número significativo conseguiu apenas incluir seu nome na lista de espera (p. 114).

Diante do exposto, surgem inúmeras questões que, embora não sejam todas respondidas por este estudo, balizam nossa reflexão: por serem, de alguma forma, um enigma, os adolescentes que cumprem uma medida socioeducativa estariam sendo colocados pelos professores no lugar de alunos-problema? Poderíamos pensar em uma possível recusa em recebê-los nas instituições de ensino, ou, se matriculados, seriam eles foco de abordagens segregativas naquele espaço institucional? Até que ponto os atos cometidos pelos adolescentes perturbariam o funcionamento escolar?

A pesquisa de Zanela (2010) revela que a representação social da escola entre os adolescentes que cumprem medidas, ou seja, a importância dela para eles, é a possibilidade de ingresso na vida profissional. Nas palavras da autora, "ainda há existência de elementos presentes no discurso dos adolescentes que demonstram uma concepção utilitária da necessidade de escolarizar-se, ante as exigências do trabalho" (Zanella, 2010, p. 18). Sabemos que a realidade da internação conta com elementos facilitadores para esse vínculo, quando as escolas se encontram dentro das unidades de internação, privilégio não vivenciado pela semiliberdade. Mas como as coordenações das medidas podem efetivar a relação do adolescente com a escola? 


\section{Os desafios da escolarização na semiliberdade}

$\mathrm{Na}$ medida de semiliberdade, não há escola dentro da casa, e o adolescente é inserido nas escolas da comunidade. Assim, a frequência depende, em grande parte, de decisão do próprio jovem. No início da consolidação da política de semiliberdade em Minas Gerais, acreditou-se que era preciso aguardar o despertar do desejo de saber ou do interesse pelo estudo antes de fazer o movimento de retomada efetiva da vida escolar do adolescente. Conforme a execução da semiliberdade avançou e novas unidades foram sendo implantadas, os adolescentes ensinaram que o valor e o lugar ocupado pela escolarização na instituição fazem toda a diferença e têm, portanto, efeitos na adesão do adolescente ao espaço escolar.

Certamente, a medida precisa ter como horizonte o despertar do interesse e do desejo pelo saber, pela escola e pelo futuro, mas não pode desconsiderar a incidência sobre o jovem do valor da escolarização transmitido pela unidade de semiliberdade. Assim, as unidades que começaram a transmitir a escolarização como eixo da medida, sua vinculação ao cumprimento e ao desligamento, e a expectativa da instituição com relação à frequência começaram a surpreenderse pelo interesse dos adolescentes pela escola, pela frequência e pelo próprio aprendizado. A execução do eixo escolarização na medida de semiliberdade chama a atenção para a importância daquilo que a instituição transmite como valor para o adolescente: a própria unidade precisa se conciliar com o lugar que a escola tem para si e para seu projeto, sendo esse o primeiro passo para a retomada da relação do adolescente com a escolarização.

Sendo a escola um eixo primordial das medidas socioeducativas, entre elas a semiliberdade, as equipes das unidades iniciam, tão logo se dá a acolhida do jovem na casa, o trabalho de retomada da escolarização, tendo como ponto de partida a trajetória de cada adolescente.

Conforme já constatado anteriormente, a maioria dos adolescentes que ingressa na medida de semiliberdade traz consigo uma relação conflituosa com a escola, culminando, muitas vezes, na sua evasão da instituição escolar.

[A] ideia ou representação que parecem ter de escola é de um espaço em que prevalecem a desmotivação, a ausência de necessidade de estudar e a baixa frequência. [...] de acordo com eles, a frequência irregular à escola e suas ausências na sala de aula são consequências de suas condições de vida precárias, da inadaptação às condições institucionais específicas da escola, da frustrada tentativa da equipe escolar em manter as regras de funcionamento e conduta, e que são detectadas por eles como um esvaziamento da autoridade (Arone, 2006, p. 71). 
Nessa perspectiva, apresenta-se ao trabalho do pedagogo, principal técnico de referência para a escolarização, um primeiro desafio: tentar despertar no jovem um interesse pela escola, para além da sua obrigatoriedade imposta por sua sentença judicial.

O segundo desafio enfrentado pelos técnicos corresponde à resistência das escolas em aceitar os adolescentes provenientes do sistema socioeducativo, descortinando um cenário no qual as equipes das unidades se veem impelidas a atuar junto a esses dois atores, isto é, o jovem e a escola. Por um lado, incentivar o adolescente a frequentar a escola, e, por outro, buscar uma parceria com escola para acolher e formar o jovem, para além da obrigação de ambos.

Vale ressaltar que essa busca por uma parceria e enlaçamento de ambos parte do pressuposto de que a estratégia de incluir os adolescentes na escola pautando-se na obrigatoriedade de um frequentar e do outro em aceitar é falha, culminando em conflitos, atuações e evasões. Pelo lado dos jovens, vê-se que chegam à medida socioeducativa pelo não cumprimento das normas e obrigações que lhe foram impostas. Nessa perspectiva, a obrigação vinda de um juiz pode igualmente não surtir efeito, ou, na melhor das hipóteses, pode fazer com que o jovem frequente a escola para "pagar de boa" a medida e, tão logo ela cesse, a frequência igualmente se finda.

No que diz respeito à escola, a existência de uma determinação judicial obrigando a direção a aceitar o adolescente garante, sem sombra de dúvida, seu o ingresso. Entretanto, não sua permanência, se não for trabalhado o preconceito e o imaginário dos professores quanto aos possíveis transtornos que o jovem pode trazer, os professores podem apresentar "resistência" ao trabalho educativo desenvolvido com os adolescentes, o que pode acarretar desinteresse destes pela escola, ou mesmo evasão escolar. Salienta-se que essa postura livre de preconceito e desconfianças por parte dos professores representa um ideal dificilmente realizável, uma vez que são raras as ocorrências de situações de segurança envolvendo os adolescentes em situação de semiliberdade no âmbito escolar belo-horizontino. Dessa forma, as equipes das unidades de semiliberdade precisam desenvolver um amplo trabalho de sensibilização com a direção e os professores para que a inserção dos adolescentes no espaço escolar se dê de forma a possibilitar o enlaçamento destes com a escola e, mais do que isso, seja capaz de implicá-los no processo educativo.

Assim, o trabalho da medida socioeducativa é desenvolver algum sentido do jovem pela escola e, para tanto, é imprescindível a participação da instituição de ensino, já que essa é sua função e que é em suas dependências que novas descobertas e novos olhares sobre a educação formal poderão surgir. 
Cabe à escola se voltar para sua função, considerando, antes de qualquer coisa, que, em algum momento, essa instituição faltou com sua obrigação de formação desse adolescente. Sobretudo a escola deve se questionar sobre o que está fazendo para manter esse jovem, que agora retorna em outro contexto, na escola, isto é, sobre como tem se esforçado para formá-lo e para diminuir defasagens de conhecimento e distorção idade-série, despertando-lhe o desejo pelo saber.

A responsabilidade pela escolarização do adolescente em cumprimento de medida de semiliberdade é compartilhada entre o adolescente, a equipe técnica que o acompanha e pela escola, sendo infrutífera essa tentativa quando algum ator declina em seu dever e quando a obrigação se sobrepõe à busca pelo enlaçamento e parceria.

\section{Considerações finais}

Neste artigo, foi possível verificar que o processo educativo coloca obstáculos tanto para o aluno, em especial o adolescente em conflito com a lei, como para a instituição escolar. Se, por um lado, os adolescentes alegam ter dificuldades para frequentar a escola devido a "guerras" na comunidade, conflitos com professores e coordenação, desmotivação e, ou, falta de tempo, uma vez que muitos precisam trabalhar e por vezes buscam por respostas e soluções imediatas; por outro, os professores argumentam que lidar com esses alunos é um desafio, pois consideram que o ECA superprotege estes, além de não responsabilizá-los por seus atos. Além disso, é comum que os professores os coloquem no lugar de "alunos-problema", segregando-os por os considerarem perigosos e propensos a desestabilizarem a ordem escolar. Assim, tratam esses adolescentes de forma diferente dos demais alunos, por não apostarem em seu potencial e na possibilidade de fazerem novas escolhas que não envolvam a prática de atos infracionais. Deparamo-nos com a reprodução de um estigma e com a perpetuação da trajetória dos jovens, sem possibilidade de instauração de uma nova dinâmica de escolarização.

Nesse sentido, a escola, mesmo que seja considerada fundamental para alguns adolescentes, pode se tornar, de certa forma, inacessível e segregacionista, em razão do mal-estar dos professores e da direção, que geralmente consideram esses jovens os únicos responsáveis pelo seu fracasso na escola, seja pela via da expulsão, da evasão ou da repetência (Santana, Oliveira \& Machado, 2012). É importante destacar também que, muitas vezes, por não saberem lidar com esses alunos, os educadores lançam mão de estratégias excludentes. Dias e Onofre (2010) assinalam que alguns diretores, ao depararam com a prática de atos infracionais dentro da escola, solicitam a transferência compulsória do adolescente, além de denunciá-lo à Vara da Infância e da Juventude. Dessa forma, Dayrell (2007) revela: 
Diante dessas representaçôes e estigmas, o jovem tende a ser visto na perspectiva da falta, da incompletude, da irresponsabilidade, da desconfiança, o que torna ainda mais difícil para a escola perceber quem ele é de fato, o que pensa e é capaz de fazer (p. 1117).

Logo, a escola parece encontrar barreiras para oferecer o lugar de vida proposto por Freud a esses adolescentes, apresentando dificuldades para acolher suas dúvidas e questôes nesse momento de transição e afastamento da família. Assim, ainda que a instituição escolar seja relevante, segundo Gallo e Willians (2008), no sentido de prevenir a reincidência de atos infracionais, o aumento da gravidade da infração e o uso de drogas, isso dificilmente é alcançado. Tornamse, então, necessárias e urgentes a construção de redes e a discussão de casos que aproximem a escola dos diversos serviços nos quais esses adolescentes possam estar inseridos, a saber: as medidas socioeducativas, a saúde, a assistência social e outras políticas públicas e serviços voltados para esse público.

Por fim, é preciso que a escola acompanhe, também pela via da construção de redes de trabalho, o "ruir dos muros" (Dayrell, 2007, p. 1115), isto é, a influência de outras instâncias sociais econômicas e culturais na instituição, como a música, em especial o rap, a dança, a moda, as artes plásticas, representadas principalmente pelo grafite, e outras formas que esses jovens encontram para se expressarem e se inserirem na sociedade.

Assim, podemos afirmar que uma intervenção junto ao adolescente autor de ato infracional deve caminhar na direção do reconhecimento humano. Zanela (2010) (como citado em Costa, 1999) defende uma Pedagogia com o foco central na relação educador/educando. A Pedagogia da Presença, como denominada por Costa (1999), precisa seguir cinco princípios: significar a presença, acolhimento por parte do educador, escuta, resgate do positivo, autoridade. Vale esclarecer que "significar presença" quer dizer apresentar uma atitude de não indiferença, ou seja, de reconhecimento do outro na sua diferença, o que nem sempre acontece; em alguns depoimentos da pesquisa de Zanela (2010) os jovens denunciam a ausência do professor.

Este é um dos maiores desafios: criar espaços para o reconhecimento humano, decisivo para construção de uma vida ética desses jovens. 


\section{Referências}

Alves, V. (2010). A escola e o adolescente sob medida socioeducativa em meio aberto. Revista Brasileira Adolescência e Conflitualidade, 3, 23-35.

Arone, M. (2006). Sentidos e significados da escola para o adolescente em semiliberdade (Dissertação de Mestrado). Pontifícia Universidade Católica de São Paulo Programa de Pós-Graduação em Educação, São Paulo.

Assis, S. G. \& Constantino, P. (2001). Filhas do mundo: infração juvenil feminina no Rio de Janeiro. Rio de Janeiro: Editora Fiocruz.

Barreto, L. (2010). O Filho da Gabriela. In Lilia Moritz Schwarcz (Org.), Contos Completos de Lima Barreto (pp 98-108). São Paulo: Companhia das Letras.

Cardoso, D. (2009). Jovens em liberdade assistida e a escola: é possível essa relação?. Revista Anagrama, 3, 1-14.

Carvalho, F. A. (2011). O adolescente autor de ato infracional x Escola: quem fala, quem escuta?. Revista Brasileira Adolescência e Conflitualidade, 4, 135-148.

Dayrell, J. (2007). A escola "faz" as juventudes? Reflexões em torno da socialização juvenil. Educação e Sociedade, 28(100), 1105-1128.

Diretoria de Gestão da Informação e Pesquisa - DGIP/SUASE (2013). Banco de Dados. Belo Horizonte: Suase.

Dias, A. F. \& Onofre, E. M. C. (2010). A educação de jovens em conflito com a lei: uma investigação de práticas escolares empregadas por diretores de escolas. In $33^{a}$ Reunião Anual da ANPED: educação no Brasil. Caxambu: ANPED. Recuperado a partir de http://33reuniao.anped.org.br/33encontro/app/ webroot/files/file/P\%C3\%B4steres\%20em\%20PDF/GT18-6616--Int.pdf

Freud, S. (2006). Contribuiçōes acerca do suicídio. In S. Freud, Edição standard brasileira das obras psicológicas completas de Sigmund Freud (J. Salomão, Trad., Vol. 11, pp. 217-218). Rio de Janeiro: Imago. (Trabalho original publicado em 1910)

Gallo, A. E. \& Willians, L. C. A. (2008). A escola como fator de proteção à conduta infracional de adolescentes. Cadernos de Pesquisa, 8, 41-59. 
Lei Federal no 8.069, de 13 de julho de 1990. (1990, 13 de julho). Estatuto da Criança e do Adolescente. Recuperado a partir de http://www.planalto.gov.br/ ccivil_03/leis/18069.htm

Lei Federal no 9.394, de 20 de dezembro de 1996. (1996, 20 de dezembro). Estabelece as diretrizes e bases da educação nacional. Recuperado a partir de http://www.planalto.gov.br/ccivil_03/leis/19394.htm

Lei Federal no 12.594, de 18 de janeiro de 2012. (2012, 18 de janeiro). Institui o Sistema Nacional de Atendimento Socioeducativo (Sinase), regulamenta a execução das medidas socioeducativas destinadas a adolescente que pratique ato infracional; e altera as Leis $\mathrm{n}^{\text {os }} 8.069$, de 13 de julho de 1990 (Estatuto da Criança e do Adolescente); 7.560, de 19 de dezembro de 1986, 7.998, de 11 de janeiro de 1990, 5.537, de 21 de novembro de 1968, 8.315, de 23 de dezembro de 1991, 8.706, de 14 de setembro de 1993, os Decretos-Leis nos 4.048, de 22 de janeiro de 1942, 8.621, de 10 de janeiro de 1946, e a Consolidação das Leis do Trabalho (CLT), aprovada pelo Decreto-Lei no 5.452, de $1^{\circ}$ de maio de 1943. Diário Oficial da Uniāo, 19 jan. 2012. Recuperado a partir de http:// www.planalto.gov.br/ccivil_03/_ato2011-2014/2012/lei/l12594.htm

Paschoal, J. D. \& Machado, M. C. G. (2009). A história da educação infantil no Brasil: avanços, retrocessos e desafios dessa modalidade educacional. Revista HISTEDBR, 9(33), 78-95. Recuperado a partir de http://www.fae.unicamp. $\mathrm{br} /$ revista/index.php/histedbr/article/view/4023

Pinheiro, V. (2013). A educação e os jovens em conflito com a lei. In S. M. Sousa (Org.), Adolescentes autores de atos infracionais: estudos psicossociais (pp. 85-101). Goiânia: Ed. da PUC Goiás.

Ribeiro, M. L. S. (2001). História da educação brasileira: a organização escolar. Campinas: Autores Associados.

Rizzo, G. (2003). Creche: organização, currículo, montagem e funcionamento. 3. ed. Rio de Janeiro: Bertrand Brasil.

Santana, F., Oliveira, M. M. \& Machado, T. F. (2012). Desafios no acompanhamento escolar. In C. M. Craidy, G. D. R. Lazzarotto \& M. M. Oliveira (Org.), Processos educativos com adolescentes em conflito com a lei (pp. 113-122). Porto Alegre: Mediação. 
Silva, I. R. O. \& Salles, L. M. F. (2009). O adolescente em liberdade assistida e a Escola. In 32a Reunião Anual da ANPED: sociedade, cultura e educação: novas regulaçôes?. Caxambu: ANPED. Recuperado a partir de http://32reuniao. anped.org.br/arquivos/trabalhos/GT03-5539--Int.pdf

UNICEF. (2011). O direito de ser adolescente: oportunidade para reduzir vulnerabilidades e superar desigualdades. Brasília: UNICEF. Recuperado a partir de http://www.unicef.org/brazil/pt/br_sabrep11.pdf

Volpi, M. (2011). (Org.), O adolescente e o ato infracional. São Paulo: Cortez.

Zanela, M. N. (2010). Adolescente em conflito com a lei e escola: uma relação possível?. Revista Brasileira Adolescência e Conflitualidade, 3, 4-22. Recuperado a partir de http://pgsskroton.com.br/seer/index.php/adolescencia/article/ view/239/224 